\title{
Effect of Epigenetic Drug Candidate Olsalazine on the Expression of CDH1 and uPA Genes in MCF-7 Breast Cancer Cell Line
}

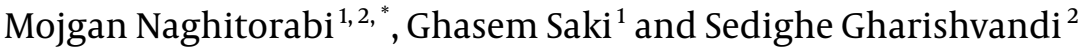 \\ ${ }^{1}$ Cellular and Molecular Research Center, Ahvaz Jundishapur University of Medical Sciences, Ahvaz, Iran \\ ${ }^{2}$ Department of Pharmacognosy, School of Pharmacy, Ahvaz Jundishapur University of Medical Sciences, Ahvaz, Iran \\ "Corresponding author: Cellular and Molecular Research Center, Ahvaz Jundishapur University of Medical Sciences, Ahvaz, Iran. Tel: +98-6133738378, Fax: +98-6133738381, Email: \\ mnaghitorabi@gmail.com
}

Received 2018 April 16; Revised 2018 December 18; Accepted 2019 January 12.

\begin{abstract}
Background: A main epigenetic change in cancer is DNA methylation, which leads to the inactivation of tumor suppressor genes. Due to its reversible nature, many studies have focused on how to correct epigenetic imbalances via inhibiting DNA methyltransferases (DNMTs). Recent studies have shown that olsalazine can be a potent candidate for DNMT inhibition.

Objectives: The current study aimed to assess the cytotoxic effect of olsalazine on MCF-7 cells and the expression of CDH1 and uPA, as cancer-related genes, compared to decitabine.

Methods: The cytotoxicity of olsalazine and decitabine on MCF-7 cells was assessed by MTT assay. To evaluate the effect of drugs on the expression of $\mathrm{CDH} 1$ and $\mathrm{uPA}$ genes, MCF-7 cells were treated with olsalazine and decitabine in concentrations below their $\mathrm{IC}_{50}$ values. After $24 \mathrm{~h}$, RNA of treated cells was extracted and then subjected to a quantitative reverse transcription-polymerase chain reaction (Q-RT-PCR).

Results: The MTT assay showed that olsalazine was more toxic $\left(\mathrm{IC}_{50}=1.75 \mathrm{mM}\right)$ in MCF-7 cells than decitabine $\left(\mathrm{IC}_{50}=3 \mathrm{mM}\right)$. Q-RT-PCR analysis showed that olsalazine can significantly increase uPA expression along with a non-significant increase in CDH1 expression. Meanwhile, no significant change was found in gene expression after treatment with decitabine.

Conclusions: This study demonstrated that olsalazine was more cytotoxic than decitabine on MCF-7 cells. Also, compared to decitabine, olsalazine could increase the expression of $\mathrm{CDH} 1$ and uPA genes. It suggests that olsalazine might be more potent than decitabine in inhibiting DNMTs, although further studies are needed.
\end{abstract}

Keywords: Olsalazine, Epigenetic, DNA Methyltransferase, CDH1, uPA

\section{Background}

Epigenetic alterations are heritable modifications on the genome, which lead to changes in the gene function without affecting the nucleotide sequences. DNA methylation is the most common epigenetic change that plays a critical role in biological processes such as X chromosome inactivation, genomic imprinting, cell reprogramming during differentiation, and regulation of gene expression in mammalian cells. Considering its role in the regulation of gene expression, defects in DNA methylation may cause several diseases, including cancer (1-4).

It's well-documented that DNA methylation patterns in tumor tissues differ largely based on their corresponding normal tissues. Cancer cells commonly represent a global hypomethylation in the whole genome along with regional hypermethylation $(2,3,5)$. These hypermethylations usually occur at the promoter of genes encoding tu- mor suppressors, adhesion molecules, and DNA repair proteins in cancer cells $(3,6)$. Several studies argued that promoter hypermethylation via silencing of tumor suppressor genes (TSGs), DNA repair genes, and adhesion molecule genes (e.g. E-cadherin (CDH1 gene)) is correlated with tumor invasiveness and progress $(5,7,8)$. Also, hypomethylation at the promoter region of oncogenes (e.g. urokinase plasminogen activator (UPA)) might cause their activation and tumor invasion $(9,10)$. As epigenetic alterations are reversible, today, there is a great interest in correcting these defects using epigenetic drugs. In this regard, DNA methyltransferases (DNMTs), which appear to be especially important for epigenetic changes, have become the focus of interest $(4,11-14)$.

Several chemical compounds have been identified as DNA demethylating agents, which generally act by inhibiting DNMTs. DNMT inhibitors, are divided into nucleoside and non-nucleoside analogues. Amongst nucleoside ana- 
logues, 5-azacytidine (Azacitidine), 5-aza-2'-deoxycytidine (decitabine), have been approved by the FDA for the treatment of myelodysplastic syndrome.

A number of clinical trials are performing on the efficacy of these drugs. Myelosuppression and neutropenic fever are reported as common side effects of these drugs (4, 14,15). A number of non-nucleoside analogues are reported to have inhibitory effects on DNMTs, such as procaine, procainamide, hydralazine, RG108, and, recently, benzothiophene, with modest effects compared to nucleoside analogues: meanwhile, cytotoxicity is less common with these drugs.

Several in vitro studies have investigated the efficacy of these compounds on decreasing the promoter methylation and inducing the expression of TSGs in cancer cells $(4,14,15)$. On the other hand, there are studies that have investigated the off-target effects of epigenetic drugs. Chik and Szyf (16) showed that treatment with decitabine can induce the expression of pro-metastatic genes (e.g. uPA) and increase the invasiveness of MCF-7 cancer cells. Many attempts have been made to find new DNMT inhibitors with more efficacy and lower toxicity. Discovering threedimensional structures of DNMTs and the use of in silico structure-based screening approaches such as computational molecular docking and quantitative structureactivity relationship (QSAR) analyses provide the ability for high-throughput screening of many natural and synthetic compounds. In this manner, not only natural compounds are screened for DNMT inhibition, but also current FDA-approved medicines can be subjected to screening in a dug repurposing study $(17,18)$. Recently, olsalazine has been identified as an active DNMT inhibitor by in silico methods, and its capability in the hypomethylation of DNA has been demonstrated in the cellular context $(19,20)$. Olsalazine (Azo-disalicylate) is an approved drug in which two molecules of 5-aminosalicylate are linked by an azo bond and is used as an oral anti-inflammatory drug for the treatment of ulcerative colitis (21). Some studies have demonstrated that olsalazine can inhibit tumor growth and induce apoptosis in a rodent model of colorectal cancer (22). Although a previous study by Benno et al. (23) had shown that olsalazine may induce mitogenic actions in the rat intestinal epithelial cell. Hence, more evidence is needed.

\section{Objectives}

Therefore the present study was designed to investigate the cytotoxic effect of olsalazine on non-invasive breast cancer MCF-7 cell line and also its effect on the expression of $\mathrm{CDH} 1$ (an intercellular adhesion molecule gene) and uPA (an oncogene) genes, compared to decitabine.

\section{Methods}

\subsection{Cell Line and Reagents}

Human breast carcinoma epithelial-like cell line MCF-7 (NCBI\# C135) was obtained from the Pasteur Institute of Iran (Tehran, Iran). Roswell Park Memorial Institute (RPMI-1640) medium, fetal bovine serum (FBS), penicillin-streptomycin solution, phosphate buffered saline (PBS), 0.05\% trypsin-EDTA, and $0.2 \%$ trypan blue were purchased from Bioidea Company (Tehran, Iran) as sterile liquids. The 3-(4,5-dimethylthiazol-2-yl)-2,5diphenyltetrazolium bromide (MTT) cell viability assay kit was obtained from Bioidea Company (Tehran, Iran). The 5-Aza-2'-deoxycytidine (decitabine) and 3,3'-Azobis 6-hydroxybenzoic acid (olsalazine) sodium powders were purchased from Sigma-Aldrich (St. Louis, MO, USA) and Santa-Cruz Biotechnology (Dallas, TX, USA), respectively.

\subsection{In Vitro Cell Viability Analysis by MTT Assay}

Breast cancer cells were grown in RPMI-1640 medium (Bioidea Company, Iran) supplemented with 10\% FBS, 100 $\mathrm{U} / \mathrm{mL}$ penicillin, and $100 \mu \mathrm{g} / \mathrm{mL}$ Streptomycin. Cells were maintained at $37^{\circ} \mathrm{C}$ in a $95 \%$ humidified atmosphere containing $5 \% \mathrm{CO}_{2}$.

The stock solution of decitabine was prepared in dimethylsulphoxide (DMSO)-milli-Q water solvent mixture (1:1), whereas olsalazine was dissolved in milli-Q water and kept at $-20^{\circ} \mathrm{C}$. Stock solutions were further diluted to working solutions in RPMI-1640 medium prior to use.

To determine $\mathrm{IC}_{50}$ values of drugs (the necessary concentration of a drug to achieve $50 \%$ inhibition in vitro), cells were seeded in 96-well microtiter plates at $5 \times 10^{3}$ cell/well density. After $24 \mathrm{~h}$ of incubation, cells were treated with decitabine or olsalazine at different concentrations (i.e. $0.1,0.3,1$, and $3 \mathrm{mM}$ ) prepared in $100 \mu \mathrm{L}$ RPMI-1640 medium supplemented with $10 \%$ FBS. No treatment was applied to control cells. Then, after $24 \mathrm{~h}$ of treatment, cell viability was assessed using a MTT assay kit (Bioidea Company, Iran) according to the kit's protocol. The absorbance was measured at $570 \mathrm{~nm}$ by a microplate reader (BioRad, USA), and the results were expressed as the mean of three replicates. Cell viability was determined as the percentage of viable cells in treated samples relative to untreated control and plotted in a graph against drug concentration. The $\mathrm{IC}_{50}$ values were calculated accordingly and used to decide the optimum doses of the drugs for further investigations. 


\subsection{Relative Gene Expression Analysis by Real-Time PCR}

To analyze the effect of drugs on CDH1 and uPA gene expression at the transcriptional level, MCF-7 cells were seeded in 24-well plates at $7.5 \times 10^{4}$ cell/well density. After $24 \mathrm{~h}$ of incubation, cells were treated with sub-lethal concentrations of olsalazine (1.5 mM) and decitabine ( $3 \mathrm{mM})$, prepared in $500 \mu \mathrm{L}$ RPMI-1640 medium supplemented with $10 \%$ FBS. Untreated cells were considered as control. After $24 \mathrm{~h}$, treatment cells were harvested. RNA extraction and DNase I treatment was performed using Quick-RNA MicroPrep kit (Zymo Research, USA), as per the manufacturer's instructions. A total of 1200 ng RNA was reverse transcribed by the HIGH CAPACITY cDNA Reverse Transcription kit (Applied Biosystems, USA) according to the manufacturer's instructions using a random hexamer.

The cDNA templates were subjected to a quantitative polymerase chain reaction (Q-PCR) to assess the expression of CDH1 and uPA transcripts. For Q-PCR, $2 \mu \mathrm{L}$ of cDNA was used in a $20 \mu \mathrm{l}$ reaction mix containing $1 \mathrm{X}$ Power SYBR Green PCR Master Mix (Life Technologies, USA) and 0.125 $\mu \mathrm{M}$ of specific primer pairs. The primer sequences used in this study are provided in Table 1 . The reaction was performed in an ABI step one plus real-time PCR system (Applied Biosystems, USA) using the following conditions: a first denaturation step for $10 \mathrm{~min}$ at $95^{\circ} \mathrm{C}$, followed by 45 repeats of the following cycle: $95^{\circ} \mathrm{C}$ for $15 \mathrm{sec}$, annealing at $53^{\circ} \mathrm{C}$ for $15 \mathrm{sec}$, and extension at $72^{\circ} \mathrm{C}$ for $20 \mathrm{sec}$. After the 45 th cycle, an optional denaturation and renaturation step was carried out for $15 \mathrm{sec}$ at $95^{\circ} \mathrm{C}$ and $1 \mathrm{~min}$ at $60^{\circ} \mathrm{C}$, followed by a melt curve step ramping from $60^{\circ} \mathrm{C}$ to $85^{\circ} \mathrm{C}$, rising $0.5^{\circ} \mathrm{C}$ per sec. The relative expression ratio of the target genes was computed based on their realtime PCR efficiencies (E) and the crossing point values (CP), using Pfaffle's equation (24). Glyceraldehyde-3-phosphatedehydrogenase (GAPDH) was used as the reference gene to normalize the data. No template control (NTC) was included in experiments. Each sample was analyzed in duplicate, and all experiments were carried out thrice independently.

\begin{tabular}{lcc}
\hline Table 1. List of Real Time PCR Primer Sequences & \\
\hline Primer Name & Primer Sequence & Product Length, bp \\
\hline CDH1F113 & 5'-TCGCTTACACCATCCTCAGCCA-3' & 113 \\
CDH1R113 & 5'-ACTCTCTCGGTCCAGCCCAGT-3' & 113 \\
\hline UPA104F & 5'-CCAAAGGCAGCAATGAACTT-3' & 104 \\
UPA104R & 5'-GTTGCACCAGTGAATGTTGG-3' & 104 \\
GAPDHF113 & 5'-CTCAACTACATGGTTTACA-3' & 113 \\
\hline GAPDHR113 & 5'-AAGATGGTGATGGGATTT-3' & 113 \\
\hline
\end{tabular}

\subsection{Statistical Analysis}

The results are expressed as mean \pm SEM (standard error of the mean). Data analysis was performed using Statistical Software for the Social Sciences (SPSS) version 16.0. One way ANOVA followed by Tukey post-hoc test and Pearson correlation analysis were used to analyze the significance between different values. Statistical difference was considered when P value $<0.05$.

\section{Results}

\subsection{Effect of Epigenetic Drug Candidates on MCF-7 Cell Viability}

After $24 \mathrm{~h}$ of treatment, the effect of epigenetic modulator candidate (olsalazine), compared to the epigenetic drug (decitabine), on MCF-7 cell viability was assessed using standard colorimetric MTT assay. The results revealed an inverse association between cell viability percentage and concentration of drugs, indicating a dosedependent effect (Figure 1). The $\mathrm{IC}_{50}$ values of olsalazine and decitabine were obtained about $1.75 \mathrm{mM}$ and more than $3 \mathrm{mM}$ in the MCF-7 cell line, respectively. The concentrations below the $\mathrm{IC}_{50}$ values, i.e., $1.5 \mathrm{mM}$ and $3 \mathrm{mM}$ for olsalazine and decitabine, respectively, were considered for treatment in further experiments.

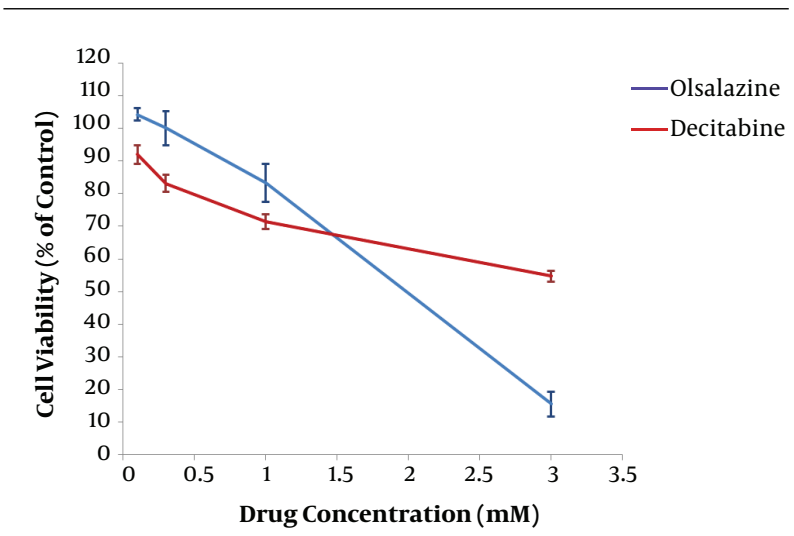

Figure 1. Effect of decitabine and olsalazine on MCF-7 cell viability. MCF-7 cells were treated with olsalazine and decitabine at different concentrations. The percentage of cell viability was determined by standard MTT assay.

\subsection{Effect of Epigenetic Drug Candidates on the Expression of $\mathrm{CDH1}$ and $\mathrm{UPA}$}

The effect of epigenetic modulator candidate (olsalazine) and the epigenetic drug (decitabine) on the expression of $\mathrm{CDH} 1$ and UPA genes was determined at the transcriptional level by quantitative real-time PCR method. For this reason, MCF-7 cells were treated with sublethal concentrations of olsalazine $(1.5 \mathrm{mM})$ and decitabine 
(3 mM) for $24 \mathrm{~h}$, and the extracted RNA was subjected to QRT-PCR. The results showed that olsalazine could increase the expression levels of CDH1 and uPA by 1.38-fold and 1.54fold, respectively, compared to untreated control cells (Table 2). In contrast, treatment with decitabine could decrease the expression of CDH1 by 0.77 -fold and of uPA by 0.84 -fold compared to the untreated cells (Table 2). Although the results concerning three independent experiments were not significant, statistical analysis showed a significant difference between treatment with olsalazine and decitabine in uPA expression (Figure 2).

Table 2. Relative Expression Levels of CDH1 and UPA in MCF-7 Cells After Decitabine/Olsalazine Treatment Compared to Untreated ${ }^{\mathrm{a}}$

\begin{tabular}{lcc}
\hline \multirow{2}{*}{ Treatment } & \multicolumn{2}{c}{ Relative Expression Levels } \\
\cline { 2 - 3 } & CDH1 Expression & UPA Expression \\
\hline Untreated & $1.00 \pm 0.00$ & $1.00 \pm 0.00$ \\
Decitabine & $0.77 \pm 0.09$ & $0.84 \pm 0.17$ \\
Olsalazine & $1.38 \pm 0.19$ & $1.54 \pm 0.12$ \\
\hline
\end{tabular}

${ }^{\mathrm{a}}$ Values are expressed as mean \pm SEM.

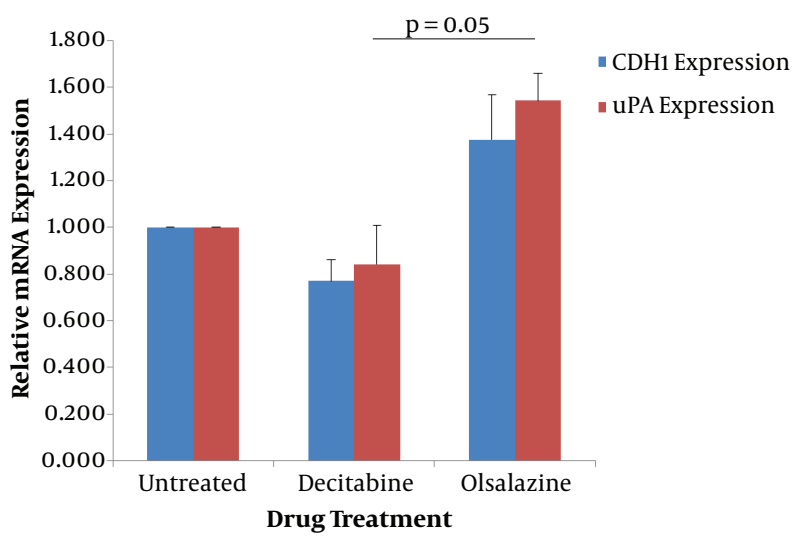

Figure 2. Effect of decitabine and olsalazine on expression of $\mathrm{CDH} 1$ and $\mathrm{UPA}$ in MCF7 cells. MCF-7 cells were treated for $24 \mathrm{~h}$ with olsalazine and decitabine, at $1.5 \mathrm{mM}$ and $3 \mathrm{mM}$, respectively. The expression levels of $\mathrm{CDH} 1$ and uPA were determined by Q-RT-PCR. The relative mRNA expressions were represented as the mean of three separate experiments. Error bars represent the standard error of means. $\mathrm{P}<0.05$ was statistically considered as significant.

\section{Discussion}

Considering the important role of DNA methylation in the epigenetic regulation of gene expression and due to the reversible nature of epigenetic changes, several studies have focused on correcting these defects via inhibiting DNMTs (13). Recent studies mentioned olsalazine as a new potent candidate for DNMT inhibition with the potential to be used in cancer epigenetic therapy $(19,20)$. Therefore, the present study was designed to assess the cytotoxic effect of olsalzine on MCF-7 cells and also its effect on the expression of CDH1 and uPA (two cancer-related genes) compared to decitabine.

In the present study, human breast cancer cell line MCF-7 was used, as it is a non-invasive human breast carcinoma epithelial-like cell line in which the uPA gene is not expressed due to hypermethylation of its promoter region (10).

To determine the cytotoxic effect of both drugs on MCF7 cells the standard MTT assay was used. The results of cytotoxicity assay showed that decitabine had no significant effect on MCF-7 cell growth at concentrations below $100 \mu \mathrm{M}$ (data have not shown); Meanwhile, a dose-dependent effect was observed in higher concentrations. The $\mathrm{IC}_{50}$ value of decitabine was more than $3 \mathrm{mM}$ in MCF-7 cells. Consistent with the results of the present study, Kastl et al. (25) showed that decitabine had no significant effect on MCF-7 and MDA-MB-231 cell growth in concentrations between 0.5 - $8 \mu \mathrm{M}$. In contrast to the findings of the present study, Ari et al. (26) have reported an $\mathrm{IC}_{50}$ value of $10 \mu \mathrm{M}$ after $48 \mathrm{~h}$ of treatment of MCF-7 cells with decitabine, which is lower than the $\mathrm{IC}_{50}$ value of decitabine in the present study. Also, Kar et al. (27) have reported an $\mathrm{IC}_{50}$ value of $15 \mu \mathrm{M}$ after 24 $\mathrm{h}$ of treatment of MCF-7 cells with decitabine.

Although cytotoxicity assay of olsalazine on MCF-7 cell showed no significant effect on MCF-7 cell viability at concentrations below $300 \mu \mathrm{M}$ (data have not shown), a dosedependent effect was observed in higher concentrations. The $\mathrm{IC}_{50}$ value of olsalazine was obtained about $1.75 \mathrm{mM}$ in MCF-7 cells, suggesting that it might be more toxic than decitabine. Also, MendezLucio et al. (20) reported that olsalazine did not have a significant effect on iHO1 cervical cancer cells at concentrations of 0.1 and $10 \mu \mathrm{M}$. However, the findings of the present study are in contrast to their results, that the toxicity of olsalazine against iHO1 cells was lower than decitabine. A previous study by Benno et al. (23) suggested that olsalazine may induce mitogenic actions in rat intestinal epithelial cells. Although other studies have shown that olsalazine is able to inhibit cell growth and induce apoptosis in bovine endothelial cells and colorectal cancer cells $(22,28)$.

The present study intended to investigate the effect of olsalazine and decitabine on the expression of CDH1 and uPA genes by the Q-RT-PCR method. The results showed that treatment of MCF-7 cells with 3mM decitabine may decrease the $\mathrm{CDH} 1$ expression, although it was not statistically significant. Previous studies demonstrated that decitabine, as a DNMT inhibitor, can induce the expression of hypermethylated silenced genes by a dose and timedependent manner (29, 30). Also, Kastl et al. (25) reported 
that the treatment of MCF-7 cells with 0.5 - $8 \mu \mathrm{M}$ decitabine can increase the expression of GAPDH. This is an important finding because in our experiments, we used GAPDH as the endogenous control, and increasing its expression may affect the expression analysis.

The present study also showed that treatment of MCF7 cells with $1.5 \mathrm{mM}$ olsalazine resulted in a non-significant increase in $\mathrm{CDH} 1$ expression. In line with the findings of the present study, MendezLucio et al. (20) indicated that olsalazine at concentrations of 0.1 and $10 \mu \mathrm{M}$ could induce the expression of methylated and silenced green fluorescent protein (GFP) gene in iHO1 cervical cancer cell. Meanwhile, in the present study, we did not find any significant difference between the effect of olsalazine and decitabine on $\mathrm{CDH} 1$ expression.

Concerning the effect of decitabine on the expression of UPA in MCF-7 cells, we found a non-significant decrease. In contrast, previous studies have shown that decitabine can induce the expression of hypermethylated genes (e.g. uPA in MCF-7 cell line), which in turn increases their invasiveness $(16,26)$. This difference can be attributed to the effect of decitabine on GAPDH expression, as discussed previously (25).

We also found that olsalazine may increase the expression level of uPA in MCF-7 cells and in this case, a significant difference was found between olsalazine and decitabine. As per previous studies, uPA is not expressed in MCF-7 cells because of its promoter hypermethylation (10). However, as reported by several studies, uPA gene expression may be induced by the use of DNMT inhibitors $(16,26,31)$. This suggests that, despite the efficacy of epigenetic drugs in reverting aberrant epigenetic changes, their off-target effects should be considered in epigenetic therapy.

In summary, this study demonstrated that olsalazine was more cytotoxic than decitabine in MCF-7 cancer cells. Also, compared to decitabine, olsalazine could increase the expression of $\mathrm{CDH} 1$ and uPA genes, suggesting that olsalazine may have more ability to inhibit DNMTs than decitabine, although further studies are needed.

\section{Footnotes}

Authors' Contribution: Mojgan Naghitorabi was contributed to study concept and design, acquisition of data, analysis and interpretation of data, and drafting of the manuscript. Ghasem Saki and Sedighe Gharishvandi were contributed to the acquisition of data, analysis, and interpretation of data.

Conflict of Interests: The authors declare no conflict of interest.
Ethical Approval: This study was approved by the ethics committee of Ahvaz Jundishapur University of Medical Sciences, Ahvaz, Iran (code: CMRC-9429).

Funding/Support: This study was financially and technically supported by the Vice-Chancellor of Research at Ahvaz Jundishapur University of Medical Sciences, Ahvaz, Iran (code: Grant\# CMRC-9429).

\section{References}

1. Nap JP, Kessel AG. Epigenetics in context. Netherlands: Plant Research International B.V. Wageningen; 2006. p. 15-45.

2. Baylin SB, Herman JG. DNA hypermethylation in tumorigenesis: epigenetics joins genetics. Trends Genet. 2000;16(4):168-74. doi: 10.1016/s0168-9525(99)01971-x. [PubMed: 10729832].

3. Veeck J, Esteller M. Breast cancer epigenetics: from DNA methylation to microRNAs. J Mammary Gland Biol Neoplasia. 2010;15(1):5-17. doi: 10.1007/s10911-010-9165-1. [PubMed: 20101446]. [PubMed Central: PMC2824126].

4. Peedicayil J. Epigenetic therapy-a new development in pharmacology. Indian J Med Res. 2006;123(1):17-24. [PubMed: 16567863].

5. Szyf M. Targeting DNA methylation in cancer. Bull Cancer. 2006;93(9):961-72. [PubMed: 16980240].

6. Das PM, Singal R. DNA methylation and cancer. J Clin Oncol. 2004;22(22):4632-42. doi: 10.1200/JCO.2004.07.151. [PubMed: 15542813].

7. Esteller M. Epigenetic lesions causing genetic lesions in human cancer: promoter hypermethylation of DNA repair genes. Eur J Cancer. 2000;36(18):2294-300. doi: 10.1016/s0959-8049(00)00303-8. [PubMed: 11094302].

8. Shargh SA, Sakizli M, Khalaj V, Movafagh A, Yazdi H, Hagigatjou E, et al. Downregulation of E-cadherin expression in breast cancer by promoter hypermethylation and its relation with progression and prognosis of tumor. Med Oncol. 2014;31(11):250. doi: 10.1007/s12032014-0250-y. [PubMed: 25260805].

9. Pakneshan P, Xing RH, Rabbani SA. Methylation status of uPA promoter as a molecular mechanism regulating prostate cancer invasion and growth in vitro and in vivo. FASEB J. 2003;17(9):1081-8. doi: 10.1096/fj.02-0973com. [PubMed: 12773490].

10. Pakneshan P, Tetu B, Rabbani SA. Demethylation of urokinase promoter as a prognostic marker in patients with breast carcinoma. Clin Cancer Res. 2004;10(9):3035-41. doi:10.1158/1078-0432.ccr-03-0545. [PubMed: 15131040].

11. Miyake T, Endo K, Honjo S, Hirooka Y, Ikeguchi M. Expression of DNA methyltransferase (DNMT) 1, 3a and 3b proteins in human hepatocellular carcinoma. Yonago Acta Med. 2010;53:1-7.

12. Girault I, Tozlu S, Lidereau R, Bieche I. Expression analysis of DNA methyltransferases 1, 3A, and 3B in sporadic breast carcinomas. Clin Cancer Res. 2003;9(12):4415-22. [PubMed: 14555514].

13. Subramaniam D, Thombre R, Dhar A, Anant S. DNA methyltransferases: a novel target for prevention and therapy. Front Oncol. 2014;4:80. doi: 10.3389/fonc.2014.00080. [PubMed: 24822169]. [PubMed Central: PMC4013461].

14. Ganesan A, Nolan L, Crabb SJ, Packham G. Epigenetic therapy: histone acetylation, DNA methylation and anti-cancer drug discovery. Curr Cancer Drug Targets. 2009;9(8):963-81. doi: 10.2174/156800909790192428. [PubMed: 20025605].

15. Foulks JM, Parnell KM, Nix RN, Chau S, Swierczek K, Saunders M, et al. Epigenetic drug discovery: targeting DNA methyltransferases. J Biomol Screen. 2012;17(1):2-17. doi: 10.1177/1087057111421212. [PubMed: 21965114]. 
16. Chik F, Szyf M. Effects of specific DNMT gene depletion on cancer cell transformation and breast cancer cell invasion; toward selective DNMT inhibitors. Carcinogenesis. 2011;32(2):224-32. doi: 10.1093/carcin/bgq221. [PubMed: 20980350].

17. Medina-Franco JL, Mendez-Lucio O, Duenas-Gonzalez A, Yoo J. Discovery and development of DNA methyltransferase inhibitors using in silico approaches. Drug Discov Today. 2015;20(5):569-77. doi: 10.1016/j.drudis.2014.12.007. [PubMed: 25526932].

18. Maldonado-Rojas W, Olivero-Verbel J, Marrero-Ponce Y. Computational fishing of new DNA methyltransferase inhibitors from natural products. J Mol Graph Model. 2015;60:43-54. doi: 10.1016/j.jmgm.2015.04.010. [PubMed: 26099696].

19. Medina-Franco JL, Mendez-Lucio O, Yoo J. Rationalization of activity cliffs of a sulfonamide inhibitor of DNA methyltransferases with induced-fit docking. Int J Mol Sci. 2014;15(2):3253-61. doi: 10.3390/ijms15023253. [PubMed: 24566147]. [PubMed Central: PMC3958909].

20. Mendez-Lucio O, Tran J, Medina-Franco JL, Meurice N, Muller M. Toward drug repurposing in epigenetics: olsalazine as a hypomethylating compound active in a cellular context. ChemMedChem. 2014;9(3):560-5. doi:10.1002/cmdc.201300555. [PubMed: 24482360].

21. Selby WS, Barr GD, Ireland A, Mason CH, Jewell DP. Olsalazine in active ulcerative colitis. Br Med J (Clin Res Ed). 1985;291(6506):1373-5. doi: 10.1136/bmj.291.6506.1373. [PubMed: 3933675]. [PubMed Central: PMC1418984].

22. Brown WA, Farmer KC, Skinner SA, Malcontenti-Wilson C, Misajon A, O'Brien PE. 5-aminosalicyclic acid and olsalazine inhibit tumor growth in a rodent model of colorectal cancer. Dig Dis Sci. 2000;45(8):1578-84. doi:10.1023/a:1005517112039. [PubMed: 11007109].

23. Benno P, Alam M, Midtvedt T, Uribe A. Sulphasalazine, olsalazine and sulphapyridine induce mitogenic actions in the rat intestinal epithelium.APMIS.1997;105(9):717-22. doi:10.1111/j.1699-0463.1997.tb05076.x. [PubMed: 9350216].

24. Pfaffl MW, Horgan GW, Dempfle L. Relative expression software tool (REST) for group-wise comparison and statistical analysis of rela- tive expression results in real-time PCR. Nucleic Acids Res. 2002;30(9) e36. doi: 10.1093/nar/30.9.e36. [PubMed: 11972351]. [PubMed Central: PMC113859].

25. Kastl L, Brown I, Schofield AC. Effects of decitabine on the expression of selected endogenous control genes in human breast cancer cells. Mol Cell Probes. 2010;24(2):87-92. doi:10.1016/j.mcp.2009.10.007. [PubMed: 19837153].

26. Ari F, Napieralski R, Ulukaya E, Dere E, Colling C, Honert K, et al. Modulation of protein expression levels and DNA methylation status of breast cancer metastasis genes by anthracycline-based chemotherapy and the demethylating agent decitabine. Cell Biochem Funct. 2011;29(8):651-9. doi: 10.1002/cbf.1801. [PubMed: 21887697].

27. Kar S, Sengupta D, Deb M, Shilpi A, Parbin S, Rath SK, et al. Expression profiling of DNA methylation-mediated epigenetic genesilencing factors in breast cancer. Clin Epigenetics. 2014;6:20. doi: 10.3389/fonc.2014.00080. [PubMed: 24822169]. [PubMed Central: PMC4013461].

28. Sharon P, Drab EA, Linder JS, Weidman SW, Sabesin SM, Rubin DB The effect of sulfasalazine on bovine endothelial cell proliferation and cell cycle phase distribution. Comparison with olsalazine, 5aminosalicylic acid, and sulfapyridine. J Lab Clin Med. 1992;119(1):99107. [PubMed: 1345796].

29. Corn PG, Smith BD, Ruckdeschel ES, Douglas D, Baylin SB, Herman JG. E-cadherin expression is silenced by 5' CpG island methylation in acute leukemia. Clin Cancer Res. 2000;6(11):4243-8. [PubMed: 11106238].

30. Zhu WG, Otterson GA. The interaction of histone deacetylase in hibitors and DNA methyltransferase inhibitors in the treatment of human cancer cells. Curr Med Chem Anticancer Agents. 2003;3(3):18799. doi: 10.2174/1568011033482440. [PubMed:12769777].

31. Cheray M, Pacaud R, Nadaradjane A, Vallette FM, Cartron PF. Specific inhibition of one DNMT1-including complex influences tumor initiation and progression. Clin Epigenetics. 2013;5(1):9. doi: 10.1186/1868 7083-5-9. [PubMed: 23809695]. [PubMed Central: PMC3727981]. 